Pemetaan Zona Korosivitas ...

\title{
PEMETAAN ZONA KOROSIVITAS TANAH BERDASARKAN NILAI CHARGEABILITY MENGGUNAKAN METODE TIME DOMAIN INDUCED POLARIZATION KONFIGURASI DIPOLE-DIPOLE STUDI KASUS PT.IPMOMI
}

\author{
Kiki Kartika Dewi, Widya Utama, Juan Pandu Gya Nur Rochman \\ Teknik Geofisika, Fakultas Teknik Sipil dan Perencanaan, Institut Teknologi Sepuluh Nopember \\ kikikade29@gmail.com
}

\begin{abstract}
Abstrak. Pipa bawah tanah menjadi elemen yang sangat penting dalam dunia industri salah satunya untuk mengalirkan fluida. Masalah serius yang sering dihadapi adalah kontak antara pipa dengan tanah dan lingkungan yang dapat menimbulkan korosi. Maka dari itu, dibutuhkan penanganan khusus agar tidak terjadi kerusakan dan ketidakstabilan tanah. Salah satu upaya awal untuk menangani hal tersebut adalah dengan melakukan pemetaan zona korosi bawah permukaan yang pada penelitian Tugas Akhir kali ini dilakukan dengan metode Time Domain Induced Polarization dengan konfigurasi dipole-dipole sebanyak 5 lintasan. Respon chargeability terhadap korosivitas tanah pada lokasi penelitian secara rata-rata menunjukkan hubungan yang berbanding lurus, semakin tinggi nilai chargeability maka semakin tinggi tingkat korosivitas tanah. Zona korosivitas tanah sangat ringan hingga sedang menyebar pada kedalaman 0-4.72 meter sedangkan zona korosivitas tanah tinggi hingga sangat tinggi berada pada kedalaman 2.724.72 meter.
\end{abstract}

Kata Kunci: chargeability, induced polarization, korosivitas tanah, PT.IPMOMI

\begin{abstract}
The underground pipe becomes a very important element in the industrial world, one of the usefulness is to flow fluid. The contact between the pipe with the soil and the corrosive environment might be a concern. A certain deal is needed to avoid damage and soil instability. One of the initial efforts to handle this problem is by conducting a mapping of the soil corrosivity zone that was conducted by Time Domain Induced Polarization method with dipole-dipole configuration of 5 trajectories. The chargeability response to the soil corrosivity at the study sites on average shows a proportional relationship, the higher the value of chargeability, the higher the level of soil corrosivity. Very mild to moderate soil corrosivity zone spreads at a distance of 0-4.72 meters while the soil corrosive zone is high up to very high at a depth of 2.72-4.72 meters.
\end{abstract}

Keywords: chargeability, induced polarization, soil corrosivity, PT.IPMOMI.

\section{PENDAHULUAN}

Perhatian akan sistem perpipaan cenderung semakin meningkat. Sistem perpipaan ini dianggap memiliki tingkat integritas yang tinggi serta lebih efektif dan efisien dibanding sistem transportasi lain. Kegiatan industri dan infrastruktur sering kali menggunakan pipa yang ditanam di bawah permukaan tanah, salah satu contohnya adalah PT.IPMOMI yang memiliki pipa bawah tanah yang berfungsi untuk mengalirkan fluida berupa air laut sebagai bahan utama produksi uap. Dalam sistem perpipaan ini kebanyakan jenis bahan pipa yang digunakan adalah jenis logam (Norin, 1998; Beaver \& Thompson, 2006), disamping keunggulannya logam juga mempunyai banyak kelemahan jika di bandingkan dengan unsur unsur lain dikarenakan sifat logam yang mudah terkorosi. Korosi adalah perusakan atau penurunan mutu dari material akibat bereaksi dengan lingkungan (Fontana, 1986). Korosivitas tanah merupakan masalah multi disiplin yang memiliki dampak terhadap keselamatan lingkungan dan struktural.

Karena bersifat korosif atau merusak maka perlu dilakukan pencegahan dengan melakukan beberapa perlakuan pada daerah yang memiliki pipa logam di bawah permukaan, salah satunya adalah dengan melakukan pemetaan zona korosivitas tanah. Metode geofisika yang biasa digunakan adalah resistivitas (Warnana dkk., 2015). Metode geolistrik yang lain seperti Induced Polarization masih jarang digunakan dalam permasalahan ini. Maka dari itu penulis ingin 
mengetahui bagaimana respon nilai chargeabilitas yang diperoleh dari pengukuran Induced Polarization terhadap tingkat korosivitas tanah. Prinsip dasar metode Induced Polarization adalah dengan mengalirkan arus listrik kedalam bumi kemudian mengamati beda potensial yang terjadi setelah arus listrik dihentikan. Konfigurasi dipoledipole yang digunakan diyakini efektif untuk memetakan zona korosivitas tanah secara lateral. Tujuan dari penelitian ini adalah untuk mengetahui respon nilai chargeability terhadap korosivitas tanah. Serta mengetahui sebaran zona korosivitas tanah berdasarkan nilai chargeability pada daerah penelitian.

\section{METODOLOGI}

Alur pengerjaan penelitian dapat dilihat pada Gambar 1.

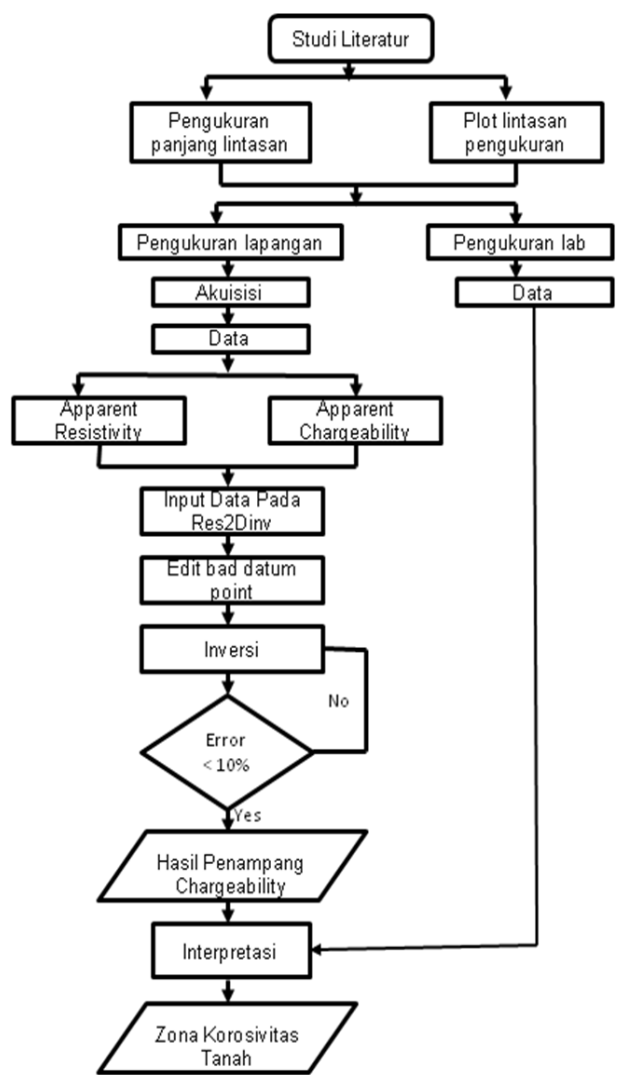

Gambar 1. Diagram Alir Penelitian.

Akuisisi data dengan target kedalaman 5 meter dilakukan dengan 2 lintasan sepanjang 72 meter, 2 lintasan sepanjang 32 meter dan satu lintasan sepanjang 54 meter. Berikut ini adalah desain akuisisi pengukuran.

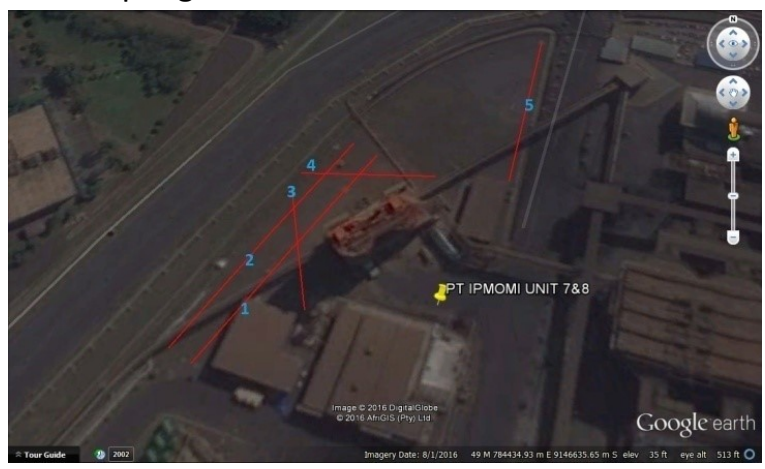

Gambar 2. Desain akuisisi pengukuran metode IP

Pengukuran metode Induced Polarization dilakukan selama 7 hari, jenis tanah pada lokasi penelitian meurupakan tanah urukan. Setelah diperoleh data dilakukan perhitungan apparent resistivity dan apparent chargeability untuk selanjutnya menjadi input pengolahan pada software Res2Dinv.

Daerah penelitian merupakan daerah pesisir dengan elevasi tanah 4.5 meter. Untuk mengetahui respon chargeability terhadap tanah atau batuan dengan intrusi air laut maka dilakukan pengukuran skala laboratorium dengan variasi konsentrasi $\mathrm{NaCl}$, yaitu $0.035,0.07,0.1,0.2,0.3 \mathrm{M}$. Berikut ini adalah gambar alat uji laboratorium yang digunakan.

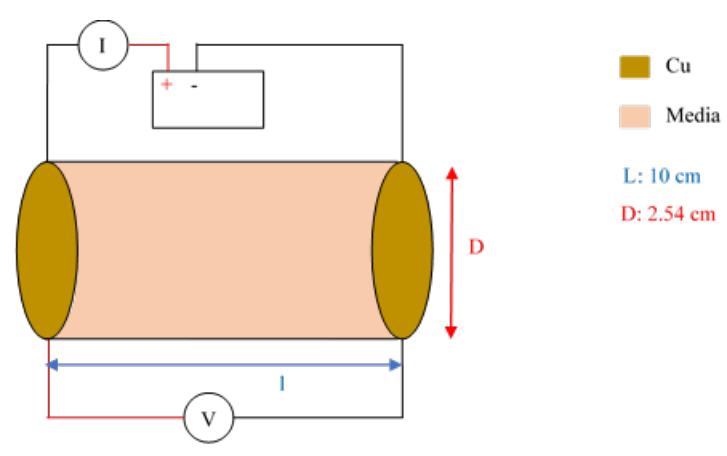

Gambar 3. Alat uji metode IP skala laboratorium

\section{HASIL DAN PEMBAHASAN}

Daerah penelitian merupakan daerah pesisir dengan elevasi tanah 4.5 meter. Rentang nilai chargeability hasil pengukuran adalah 0-1 msec, dan rentang tersebut kurang merepresentasikan daerah 138 
berasal dari batuan vulkanik pegunungan ringgit. Adanya pengaruh dari air laut mungkin saja dapat mempengaruhi kecilnya nilai chargeability. Untuk mengetahui respon chargeability terhadap tanah atau batuan dengan intrusi air laut maka dilakukan pengukuran skala laboratorium dengan variasi konsentrasi $\mathrm{NaCl}$, yaitu 0.035, 0.07, 0.1, 0.2, 0.3 M. Nilai konsentrasi itu dipilih sebagai asumsi mendekati konsentrasi $\mathrm{NaCl}$ pada air laut. Pemilihan medium pasir karena mudah diperoleh namun tetap dengan rentang nilai chargeability yang sama dengan litologi sekitar yaitu vulkanik. Dari percobaan yang telah dilakukan diperoleh hasil sebagai berikut.

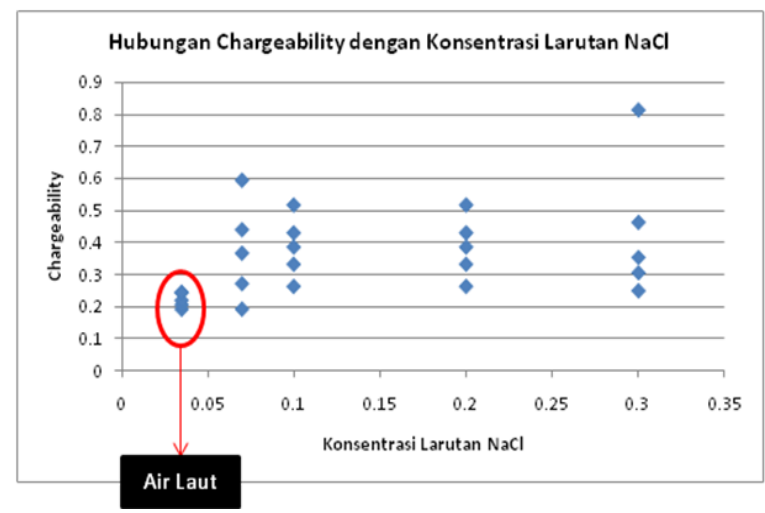

Gambar 4. Grafik Hubungan Chargeability dengan Konsentrasi Larutan $\mathrm{NaCl}$

Dari grafik tersebut dapat dilihat bahwa pada konsentrasi $\mathrm{NaCl}$ sebesar 0.035 yang mana merupakan representasi kandungan garam dalam air laut, nilai chargeability berkisar pada 0.2-0.3 msec. Hal tersebut menunjukkan bahwa nilai chargeability pasir yang harusnya berkisar antara 100-500 msec dapat turun menjadi 0.2-0.9 akibat adanya kandungan garam. Sejalan dengan penelitian yang telah dilakukan oleh (Aryaseta, 2016) bahwa nilai intrusi air laut bernilai $0.2 \mathrm{msec}$. Semakin banyak kandungan larutan garam pada pasir maka nilai chargeabilitynya cenderung semakin meningkat. Hal tersebut dikarenakan semakin tinggi kandungan garam pada suatu medium maka semakin tinggi pula tingkat konduktivitasnya. Semakin tinggi konduktivitas nilai chargeabilitynya pun akan semakin tinggi. Nilai yang diperoleh pada uji laboratorium menunjukkan orde $10^{-1}$.
Prinsip metode IP adalah mengalirkan arus listrik kedalam bumi dan mengamati beda potensial yang terjadi setelah arus listrik dihentikan. Pada saat arus diinjeksikan, ion-ion dalam pori-pori batuan akan teridistribusi dari posisi stabil menjadi tidak stabil. Ketika arus diputus, seharusnya beda potensial langsung menjadi nol, akan tetapi pada medium-medium tertentu beda potensial tidak langung menjadi nol dikarenakan medium bersifat seperti kapasitor (menyimpan senergi listrik). Energi listrik masih tersimpan dalam bentuk energi elektrokimia pada fluida elektrolit maupun mineral konduktif pada pori-pori batuan. Jadi setelah arus diputus, ion-ion yang sebelumnya mengalami pengkutuban berangsur-angsur kembali ke keadaan seimbangnya dengan kata lain masih terdapat beda tegangan yang akan meluruh terhadap waktu sampai nilainya menjadi nol (Telford, 1990). Maka dari itu pada batuan dengan kandungan mineral tinggi waktu peluruhannya semakin lama sehingga nilai chargeabilitynya semakin besar.

Hasil inversi resistivitas dan chargeability menunjukkan bahwa litologi daerah penelitian merupakan alluvium dengan resistivitas sebesar 3333 ohm.m dan chargeability sebesar 0.1-1.8 msec. Hasil inversi menunjukkan bahwa mayoritas tingkat korosivitas tanah daerah penelitian pada kedalaman 0-2 meter berada pada tingkat yang sangat ringan. Pada kedalaman 2-3 meter dari permukaan mulai menunjukkan tingkat korosivitas yang lebih bervariasi mulai dari sedang hingga sangat tinggi.

Sifat korosivitas tanah telah banyak diketahui berdasarkan nilai resistivitas namun masih sangat jarang dihubungkan dengan nilai chargeability. Maka dari itu belum ada acuan pasti mengenai hubungan antara korosivitas dan chargeability. Sehingga penulis mencoba menghubungkan antara nilai ketiganya berdasarkan zonasi yang sama. Untuk mengetahui respon nilai chargeability terhadap korosivitas tanah khususnya pada daerah penelitian. Berikut ini adalah Tabel 1 yang menunjukkan hubungan antara tingkat korosivitas tanah, reesistivits dan chargeability.

Tabel 1. Hubungan antara tingkat korosivitas tanah, reesistivits dan chargeability

\begin{tabular}{|l|l|l|}
\hline Tingkat korosivitas & Resistivitas & Chargeability \\
\hline Sangat Tinggi & $0.98-6.33$ & 0.7979 \\
\hline Tinggi & $7.33-19.81$ & 0.5080 \\
\hline Sedang & $20.25-49.81$ & 0.2513 \\
\hline
\end{tabular}




\begin{tabular}{|l|l|l|}
\hline Ringan & $50.03-99.68$ & 0.1709 \\
\hline Sangat Ringan & $100.01-1882.4$ & 0.1474 \\
\hline
\end{tabular}

Nilai chargeability berbanding lurus dengan tingkat korosivitas tanah hal tersebut disebabkan ketika suatu tanah bersifat lebih konduktif daripada lingkungannya maka nilai chargeabilitynya cenderung lebih tinggi. (Alaminiokuma, 2010) mengatakan bahwa tanah yang konduktif menyebabkan adanya jalur yang menghubungkan antara anoda dan katoda pada proses terjadinya korosi. Hal tersebut berarti semakin konduktif suatu media maka semakin membuka jalan untuk terjadinya korosi. Namun sebaran nilai chargeability tidak selebar resistivitas. Sehingga pada pengaplikasiannya nilai chargeabilitas memberikan hasil zonasi yang lebih teliti dikarenakan range yang lebih kecil.

Pada beberapa data masih dapat ditemukan tingkat korosivitas yang sama namun pada lintasan yang berbeda memiliki nilai yang berbeda. Sehingga nilai yang sama dapat ditemukan pada tingkat korosivitas yang berbeda. Hal tersebut kemungkinan disebabkan karena nilai chargeability sensitif terhadap kandungan mineral dari tanah atau batuan. Sehingga belum tentu pada nilai chargeability yang sama memiliki tingkat korosivitas yang sama. Atau pada batuan dengan kandungan mineral yang sama bisa saja memiliki tingkat korosivitas yang berbeda. Persebaran nilai chargeability dapat dilihat pada Gambar 3 berikut ini

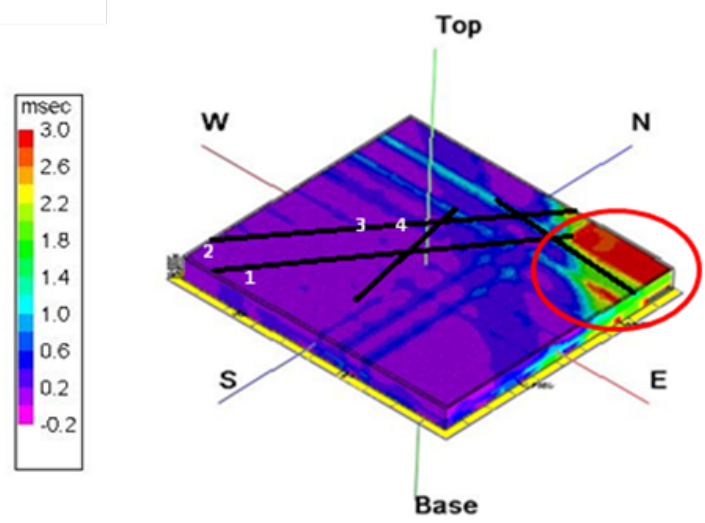

Gambar 5. Penampang 3D Chargeability
Berikut ini adalah penampang 3D dari zona korosivitas tanah berdasarkan nilai chargeability.

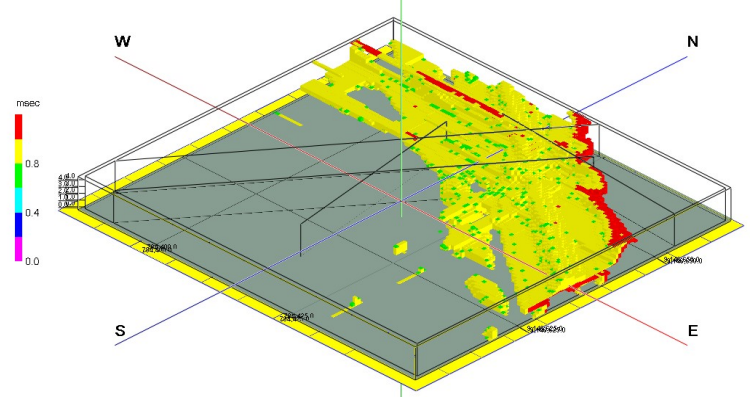

Gambar 6. Zona korosivitas tanah sangat tinggi (kedalaman2.72-4.72 meter)

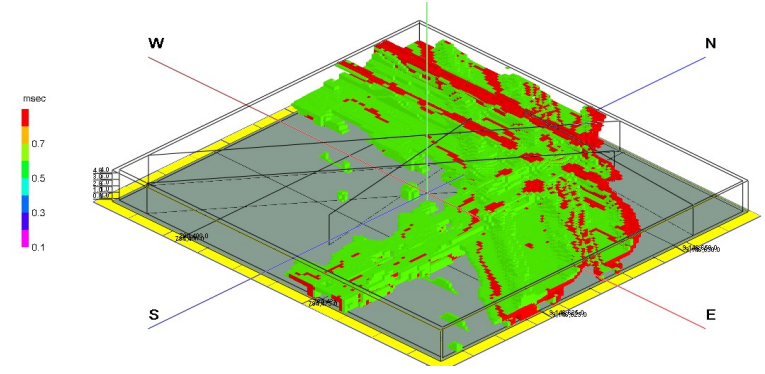

Gambar 7. Zona korosivitas tanah tinggi (kedalaman 2.36-4.72 meter)

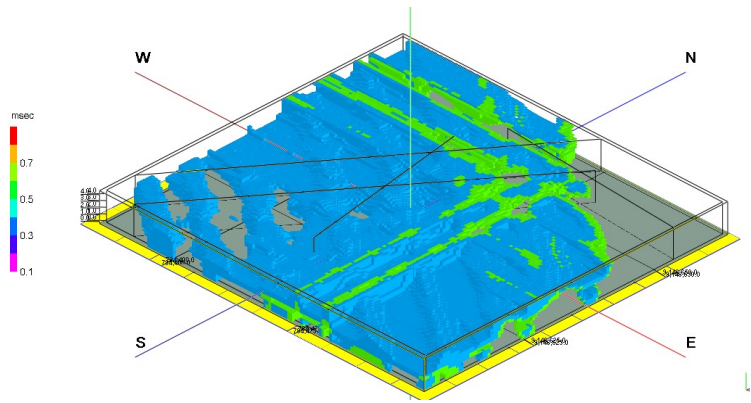

Gambar 8. Zona korosivitas tanah sedang (kedalaman 2.04-3.57 meter)

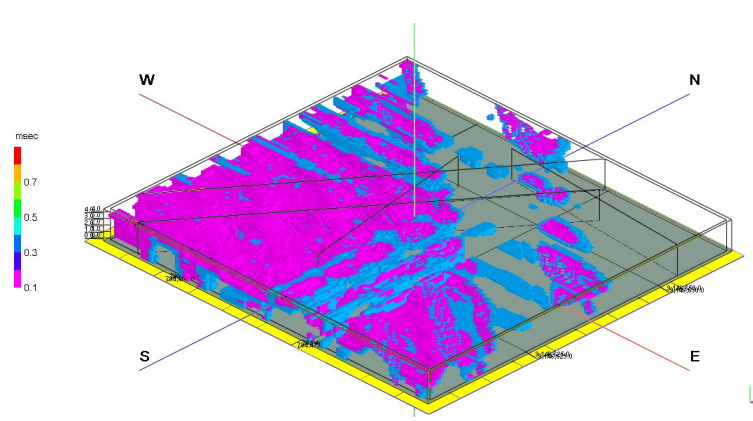

Gambar 9. Zona korosivitas tanah ringan (kedalaman 0.53-2.04) 


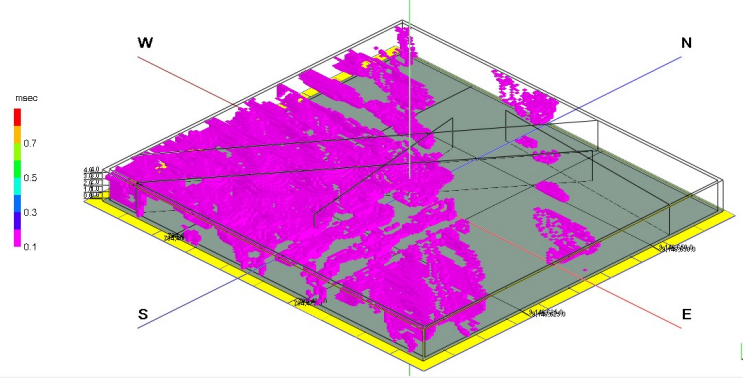

Gambar 10. Zona korosivitas tanah sangat ringan (kedalaman 0.26-1.85)

Zona korosivitas tanah sangat ringan hingga sedang menyebar pada kedalaman 0-4.72 meter dengan rentang nilai chargeabiity $0.1474-0.2513$ msec. Sedangkan zona korosivitas tanah tinggi hingga sangat tinggi berada pada kedalaman 2.724.72 meter dengan rentang nilai chargeability 0.5080-0.7979 msec. Lingkaran merah menunjukkan zona korosivitas sangat tinggi, respon yang sama ditunjukkan pada penampang 2D native potential berikut ini.

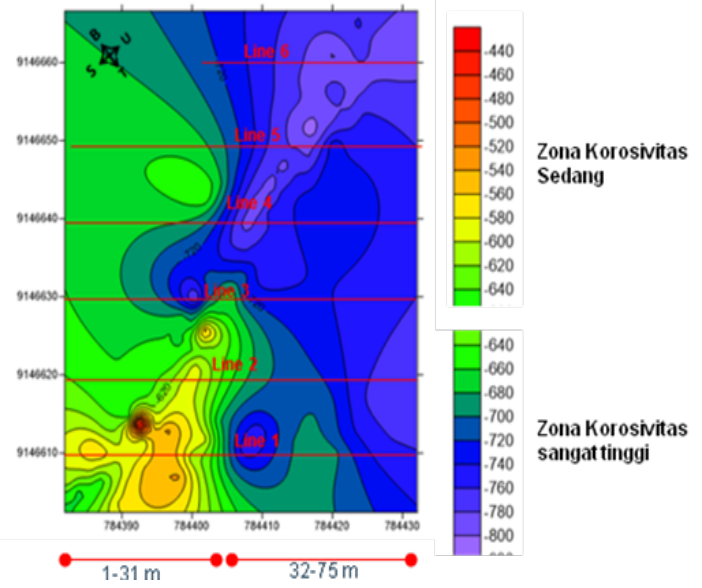

Gambar 11. Penampang 2D Native Potential daerah penelitian (Amalia, 2017)

Zona korosivitas tanah secara lateral seperti yang ditunjukkan pada gambar 3 dan 4 menunjukkan bahwa pada sisi timur laut daerah penelitian menunjukkan tingkat korosivitas yang sangat tinggi hal tersebut ditunjukkan pula pada penampang 2D native potensial bahwa pada sisi timur laut daerah penelitian memiliki range native potensial -700 hingga $-820 \mathrm{mV}$ yang mengindikasi tingkat korosivitas yang sangat tinggi yaitu $<-600$ $\mathrm{mV}$.

\section{Simpulan}

Dari penelitian yang dilakukan dapat disimpulkan bahwa respon chargeability terhadap korosivitas tanah pada lokasi penelitian secara ratarata menunjukkan hubungan yang berbanding lurus, semakin tinggi nilai chargeability maka semakin tinggi tingkat korosivitas tanah. Zona korosivitas tanah sangat ringan hingga sedang menyebar pada kedalaman 0-4.72 meter sedangkan zona korosivitas tanah tinggi hingga sangat tinggi berada pada kedalaman 2.72-4.72 meter.

\section{Saran}

Saran yang dapat diterapkan berdasarkan hasil penelitian adalah evaluasi proteksi katodik yang telah digunakan pada PT.IPMOMI berdasarkan zona korosivitas tanah. Selain itu, perlu dilakukan pengembangan range hubungan antara chargeability dengan korosivitas pada beragam lingkungan.

\section{Ucapan Terima Kasih}

Penulis menggucapkan terimakasih kepada Dr. Widya Utama, DEA dan Juan Pandu GNR S.Si, M.T selaku pembimbing yang telah meluangkan banyak waktu untuk memberikan bimbingan dan arahan kepada penulis.

\section{DAFTAR PUSTAKA}

Alaminiokuma, G. I.*, Osokpor, J.*, Emudianughe, J. E.* and Warmate, T. 2010. Delineation of Soil Corrosivity Regimes Along Petroleum Pipeline Routes in the Geomorphic Zones of the Niger Delta using 2D Resistivity Tomography

Amalia, 2017. Pemetaan Lingkungan Korosi Bawah Permukaan Menggunakan Metode Self-Potential Pada Daerah Unit 7 Dan 8 PT.IPMOMI

Beavers, J.A., Thompson, N.G. 2006. External Corrosion of Oil and Natural Gas Pipeline. ASM Handbook Volume 13C, Corrosion: Environments and Industries. ASM International.

Cramer S.D. and Jr. Covino B.S. 2003. ASM Handbook Volume 13A Corrosion: Fundamentals, Testing, and Protection, ASM International.

Fontana, Mars.G 1986, "Corrosion Engineering”, 3rd Edition, Mc Graw-Hill Book Company, Singapore. 
Keller, G. V. dan Frischknecht, F. C. 1966. Electrical Methods in Geophysical Prospecting. In international series of monographs in Electromagnetic Waves, 10, eds. A.L. Cullen, V. A. Fock, and J. R. Wait. Oxford: Pergammon Press.

Koch, G., Brongers, M.P.H., Thompson, N.G., Virmani, Y.P., Payer, J.H. 2002. Corrosion Costs and Preventative Strategies in the United States. Publication No. FHWA-RD-01-156. U.S. Federal Highway Administration Washington, U.S.A.

Loke, M.H. 1999. Electrical Imaging Surveys For Environmental And Enginering Studies. Malaysia. Penang.

Norin, M. 1998. Groundwater and Soil Properties in an urban Environment and their effects on the Corrosion of Soil Buried Constructions of Carbon, Steel, and Zinc. Department of Geology, Chalmers University of Technology. Goteborg.

Puslitbang Metalurgi-LIPI, 1987. Korosi dan Penanggulangannya.

Reynolds, J.M., 1997. An Introduction to Applied and Environmental Geophysics. New York:John Willey and Sons.

Saputro Bayu, dkk. (2010). Panduan Praktikum Geolistrik. Yogyakarta: Prodi Teknik Geofisika. Fakultas Teknologi Mineral. UPN Yogyakarta.

Telford, W.M., L.P. Geldart, , R.E. Sheriff, dan D.A. Keys. 1982. Applied Geophysic. London : Cambridge University Press

Warnana, D.D., Iswahyudi, A., Prabawa, S.E., 2015. Penentuan Area Korosi Tanah Lokal Berdasarkan Resistivitas Tanah untuk Perancangan Sistem Proteksi Katodik. J. Geosaintek 1, 43-46 